\title{
Psychometric Properties of the Attitudes Scale towards Electronic Tests among Graduate Students
}

\author{
Mo'en Salman Alnasraween ${ }^{1, *}$, Nusaiba Ali Almousa ${ }^{1}$, Jehad Ali Almomani ${ }^{1}$, Raeda Mofid Ammari ${ }^{2}$ \\ ${ }^{1}$ Faculty of Education and Psychology, Amman Arab University, Amman, Jordan \\ ${ }^{2}$ Faculty of Arts and Science, Amman Arab University, Amman, Jordan
}

Received September 24, 2020; Revised December 1, 2020; Accepted December 13, 2020

\begin{abstract}
Cite This Paper in the following Citation Styles
(a): [1] Mo'en Salman Alnasraween, Nusaiba Ali Almousa, Jehad Ali Almomani, Raeda Mofid Ammari, "Psychometric Properties of the Attitudes Scale towards Electronic Tests among Graduate Students, "Universal Journal of Educational Research, Vol. 8, No. 12B, pp. 8262-8273, 2020. DOI: 10.13189/ujer.2020.082631.
\end{abstract}

(b): Mo'en Salman Alnasraween, Nusaiba Ali Almousa, Jehad Ali Almomani, Raeda Mofid Ammari (2020). Psychometric Properties of the Attitudes Scale towards Electronic Tests among Graduate Students. Universal Journal of Educational Research, 8(12B), 8262-8273. DOI: 10.13189/ujer.2020.082631.

Copyright $\odot 2020$ by authors, all rights reserved. Authors agree that this article remains permanently open access under the terms of the Creative Commons Attribution License 4.0 International License

\begin{abstract}
The current study aimed at identifying the Psychometric Properties of attitudes scale towards electronic tests among graduate students, the researchers briefly explained various electronic test types used to asses students achievement. The study's significance lied in providing a valid and reliable scale, as well as demonstrating the appropriateness of electronic tests whether they meet the aims of distance education or not. Thus, universities can develop the tests' quality and improve them. The sample of the study consisted of (690) students (male and female) of the Amman Arab University. A scale of (56) items was built for the study. Different procedures were done to assure the validity of the scale such as Exploratory factor analysis, construct validity, and discriminatory validity, as for the reliability Cronbach's Alpha, Split Half, Standard Error of Estimate, and Hoyt equation were used. All these indications showed appropriate and reasonable results for the scale. The arithmetic means and standard deviations of students' attitudes towards electronic tests were calculated. The statistical results showed that the attitude scale has acceptable psychometric properties, as students had positive ones. It also showed statistical differences in students' attitudes attributed to gender in favour of female students due to their personal circumstances. However, there were no statistical differences found attributed to faculty or to the interaction between faculty and gender. The general results of this scale could encourage other researchers to implement it on various universities in different countries and to integrate technology with
\end{abstract}

traditional teaching in their coming courses.

Keywords Psychometric Properties, Attitudes towards Electronic Tests, Assessment

\section{Background Research}

In light of the contemporary world, we have witnessed a scientific and technical revolution, which has led to the e-learning expansion circle through global interactive educational platforms and channels. In addition, Distance learning was developed for teaching students synchronously or asynchronously at any time regardless of their different geographical locations. After the emergence of the Corona pandemic (COVID-19) in the world, the interest in remote learning has increased dramatically. The need for finding new valid electronic evaluation methods and ways to verify these types of education quality as well as its educational outcomes have expanded. Thus, the efficiency and effectiveness of the interactive educational program have been implemented in numerous courses.

With the beginning of the twenty-first century, interest in computerizing education and employing technology in various aspects of the educational, administrative, and teaching process, in addition to the communication processes concerned with educational institutions has increased. Despite all this interest in developing the 
educational process, evaluations and tests did not receive much attention and the problem remained. The biggest challenge for modern education is that the evaluation tools with which we try to measure students' skills today are the same as yesterday's tools. From this point, it was necessary to increase interest in the field of evaluating the educational process and developing it to keep pace with the requirements of our time by adapting to its changes that led to the electronic evaluation emergence [16, 27].

The electronic assessment is the use of information technology in conducting the evaluation process and executing the tests electronically. The universities use a group of different methods and means to carry out these tests through the Learning Management System or through some available applications such as the Zoom application, Google Classroom, Microsoft Teams, or through Google Forms, e-mail, or social media available such as Facebook. The design of these electronic tests are affected by several factors, including the educational goals of the educational stage, the characteristics of the learners and their skills, and they appear in many forms and vary in terms of their design and purpose which are the most prominent forms of electronic tests [2,10,21,29].

The electronic assessment must balance the needs of technology, and learning results. That is, a wide range of online programs, and assessment criteria are needed to assess student learning successfully and carefully while meeting the challenges of accountability, improvement of students' learning. Consequently, it is highly recommended that educators continue to research this mode of instruction to develop well-organized and effective assessment techniques to have accountability for student results in online learning [12].

\subsection{Techniques Used for Electronic Tests Assessment}

The use of a variety of methods to assess student learning in online courses is highly suggested as students are different and their style of learning varies [6, 24].

- Objective electronic tests (multiple choices): The questions of these tests offer an option in the electronic tests for formative evaluation, diagnostic evaluation, and synthesis assessment that depend on space and time. These tests have stability and comprehensiveness of educational content, ease of correction, and achieve objectivity in the correction process. Implementing these tests electronically and correcting them easily within a short period are enough reasons for teachers to be encouraged to use them. Besides, students tend to like it, especially those who prefer memorization, as it is one of the most used electronic tests. On the other hand, these tests have some disadvantages; first, they are represented in their inability to assess and apply problem solving and measure higher thinking skills. Second, these tests easily allow cheating and guesswork and do not help the student to show his various mental skills in analyzing, interpreting, and expressing the extent of his understanding of the material [5, 15]. In addition, preparing these tests appropriately requires time and skill on the part of teachers. In order to improve these types of tests, some universities resort to providing a bank of reviewed and revised questions for each course that the teacher can choose from to facilitate the task of applying these tests. [9] claimed that assessment requires teachers and their respective institutions to develop high standards for learning. Besides, they can establish well-organized assessment methods for determining how well the standards have been met as well as to make improvements [14].

- Essay Electronic tests: These tests present specific limited questions form, where this type of test depends on the freedom of organizing the required answers. The students show their ability to choose the ideas, and knowledge they have acquired in these questions. They learn how to relate and integrate them to solve new problems. Students should pay attention to use proper words and expressions to answer the required questions. Despite these advantages, the essay tests do not cover the curriculum due to the limited number of questions compared to the aim of these tests, and their correction is subjective according to the teachers, which may affect the result of validity.

- Short electronic tests: These tests are given to students during distance learning synchronously or asynchronously. These tests focus on the acquired knowledge level by measuring the ability to recall simple conceptual and procedural information. These tests verify the effectiveness of students' participation and understanding of the learning course content, which does not need a long time to be answered by the students.

- Open book exam: These exams usually evaluate students' higher thinking skills by measuring their ability to apply their knowledge and ability in solving various problems in real situations. The teachers can give and control these exams synchronously or asynchronously by the learning management system. Furthermore, when teachers might face some technical problems, they are solved by sending the exam by e-mail. Moreover, Foder [11] explained how teachers, in this type of exam, have a greater challenge to ensure academic honesty. Thus, the teachers can detect any fraud or by using the (Turnitin) program which could check citation plagiarism easily [26].

Besides, they help in distinguishing students' ability to enhance their retrieval of information, the acquired knowledge and self-learning skills by students seeking proper educational materials, and having access to information and references resources away from the 
anxiety of examinations. As well as enhancing students' reading and summarization skills. This type of examination requires more effort and time for students to search for the necessary information. It also requires students to have the skill of linking, summarizing, and understanding according to the gathered information. Open book exam effectiveness is great because teachers provide honest feedback regarding students' learning and achievement $[22,24]$.

- Projects: Projects are sometimes used in special courses or they are used as graduation projects. They are stored in the Learning Management System. Projects are done individually or by a group. These projects allow students to apply higher-thinking skills such as critical thinking and problem -solving. Sometimes projects are considered an alternative to the final exam. These projects are distinguished for enabling students to employ and apply what they have learned within a practical and scientific project. The projects discussions are done in front of the teacher and other colleagues at a scheduled time. This type of assessment requires the teacher's skill in verifying these projects and ensuring their authenticity and reliability.

- Electronic Portfolio: This is an achievement file, which is one of the methods of students' performance evaluation, and it includes collecting the student's educational work electronically, and samples of the student's assignments during the semester as evidence of his accomplishment of the course learning outcomes. The electronic achievement data portfolio is easily copied on CDs and stored in various forms of files (audio, visual, video, and text) with the least capacity in one place by the teachers. It enables students to obtain computer experiences, technical skills, the ability to use multimedia in their work, and allows them to give and evaluate it by the teacher in electronic form.

According to what was mentioned before, the advantages of the electronic assessment have significant points, most notably: 1) flexibility in providing exams, whether by presenting them simultaneously or at different times for a large group of students in different places. 2) The fairness and transparency in the evaluation are present, especially the objective questions through automatic correction.3) The results and feedback are available immediately after answering all the questions, and the possibility of direct analysis of the students' performance level, which allows teachers to evaluate the questions in terms of indicators of difficulty and discriminatory ability, [28].

Formative evaluation is also useful in reviewing the learning process and providing feedback that supports more learning by giving a variety of clearly explained assignments on a weekly basis $[18,24]$.

As for the disadvantages of electronic tests, they have represented in the following points: the need for an equipped electronic environment and the presence of a technical support team, and it is difficult to measure higher skills and correct the essay questions. Another point to consider is the preparation of questions requires a long time, effort, training, and skill on the part of the teacher. Besides, these tests may increase the possibility of cheating in them from various sources $[1,8]$.

Social and educational psychological attitudes are very important issues, psychosocial attitudes are among the most essential social upbringing outcomes at the same time they are among the most vital motivational behaviour that plays a fundamental role in controlling and directing it. In general, the functions of education are important as young people have attitudes that help them adapt to the requirements of their times, and that they work to change the undesirable attitudes that may hinder social development. Attitude is a set of ideas, feelings, perceptions, and beliefs about a topic that directs the behaviour of the individual and determines his place on that subject. In fact, psychological attitudes are acquired and formed through learning processes where they are relatively stable and permanent, but that does not mean the impossibility of changing or modifying them. As it is possible to change many of the attitudes of individuals towards different topics, through special programs that target specific changes in the psychological direction of the individual in one way or another. On this basis, a set of basic principles are observed in an attempt to change the attitudes of individuals [30].

The process of formation or acquisition of psychological attitudes is dynamic. In other words, it is the outcome of complex interactions between the individual and the limits of his physical and social environment, so that through multiple channels of this interaction, psychological attitudes can be absorbed and acquired. The components of psychological attitudes are the cognitive component that is represented in all the cognitive processes, beliefs, and ideas that the individual has related to his attitude, and it includes his arguments that stand behind his acceptance of a specific attitude. The emotional (sentimental) component: it manifests itself through the person's feelings and desires about the topic, and from his interest in it or his aversion to it, and his love or hatred for it. The behavioural component: the direction for a specific manner is evident in the practical reaction. Besides, attitudes are considered as behavioural guides for a person, which pushes him to act in a negative way when he has negative attitudes towards these topics [25].

It was necessary to verify the psychometric properties of these electronic tests. The verification of electronic or non-electronic tests for their availability is done in advance. Objectivity is one of these features, where teachers are subjective in their test correction, as well as the validity, which indicates the test has measured what it was prepared for. The reliability of the test refers to obtaining the same results when retesting the same group 
and measuring the comprehensiveness of all components. The electronic assessment can give a credible assessment when applying the integrity control and validity procedures, as a good test that supports understanding, verification of knowledge, and achieving the objectives of the course. In addition, the electronic question bank has an assortment of questions in terms of their level of difficulty and coverage of all aspects of the educational content. Teachers make sure that a good test model comes out with certain specifications that assure worthy evaluation for all students of all academic levels, thus, it could be relied upon $[19,33]$

\section{The Problem of the Study}

Recently, the world witnessed difficult circumstances and challenges. The most prominent is the spread of the Coronavirus, which has ended the lives of millions of people in the world, and led to the collapse of the economy in most countries of the world since life activities ceased in various fields to limit the spread of this global epidemic. As a result, the countries of the world needed to search for alternatives to make sure the continuation of the educational process in their societies without exposure to the dangers of this epidemic. Therefore, distance education and e-learning methods application were the best means for the current situation. For the reason given, a kind of competition appeared among educational institutions in providing education services at a distance through global educational platforms. Teachers applied utmost efforts to achieve high-quality electronic services in the implementation of the educational process remotely through these platforms and other electronic communication channels. Furthermore, the university increases the training and motivation of learners and teachers to use distance education to achieve high-quality educational outcomes.

Electronic tests implementation is the base of Distance learning evaluation through the learning management system at the university or by using educational platforms or websites specialized in creating and applying electronic exams simultaneously. Nevertheless, earlier studies such as [7] show that teachers still do not trust electronic tests and question their efficacy. They tend to use traditional paper-based tests as the most reliable results. Hence, it was necessary to have a scale to verify the quality of the electronic tests and to find the psychometric properties of this scale for approval by researchers and those interested in building electronic tests. This is what the current study intends to achieve; it aims to determine the psychometric properties of the scale for accessing the quality of the electronic tests for graduate students at Amman Arab University, and this is done by answering the following questions:

1. What are the indications of the validity of the attitude scale towards electronic tests?
2. What are the indications of the reliability of the attitude scale towards electronic tests?

3. What are the attitudes of graduate students in Jordan towards electronic tests?

4. Do graduate students' attitudes towards electronic tests differ according to gender and faculty?

\subsection{The Significance of the Study:}

The study is important because the researchers built a scale with good appropriate psychometric properties for the students' attitudes towards electronic tests. In addition, to detect the strengths and weaknesses in electronic tests from the students' point of view as they do these tests. The students' feedback about the experience and quality of electronic tests, and its suitability to meet the goals of distance education is essential so that educational institutions in general and universities in particular, including Amman Arab University, can improve these tests quality and develop them. In return, this would help the teachers or researchers to benefit from the scale to know students' attitudes towards electronic tests and build their own tests with good properties or adapt them to the needs of their students.

\subsection{Procedural Definitions:}

Psychometric Properties: They are statistical indications or evidence of the scale of the electronic tests quality and scale validity represented what it should measure and the degree of its stability by obtaining the same results when re-applying it to the same sample. However, the sample member's total degree that they get on the scale indicates the validity.

Electronic Tests are a way to evaluate graduate student's performance remotely at the university simultaneously using the Internet through the Learning Management System, or through websites for preparing an electronic test, for example, a set of various questions (essay tests), and goal tests such as Multiple choice, true and false, fill in the blank, ... and others.

\subsection{Limitation of the Study}

This study was restricted to Amman Arab University students in the master's stage for the second semester of the academic year (2019/2020). The possibility of generalizing the results of this study is limited by the validity and reliability of the study tools, the correct procedure of conducting the study, and the sincerity of the respondents of the study sample.

\section{Literature Review}

Scanlon [25] conducted his study to investigate the students' attitudes towards electronic tests, focusing on the 
feedback. The sample of the study consisted of (40) students from the University of Birjand. The results proved that students' attitudes were very contradicting in the instant feedback features of electronic tests. Students' perceptions about instant feedback were conflicting because some felt immediate feedback is stressful, while others considered it pleasing. Therefore, teachers should personalize e-test feedback according to students' preferences.

According to Peytcheva-Forsyth et, al [23] believe the attitudes of students toward online learning and distance education has a major role in developing and implementing pedagogically effective online curricula. This would also assist the process of accrediting more distance education courses at Sofia University (Bulgaria). The paper studied the attitudes of (590) undergraduate students of Sofia University towards online learning and distance education. The main purpose of the study is to find out the influence and dependencies of different factors on these students. The results indicated a positive attitude towards online courses as well as the demographic factors that affect students.

Vasilevska et, al [32] conducted a study titled 'Assessment of Readiness for Distance Learning in European Universities', aimed to discuss the most important challenges facing e-learning, especially electronic assessment and its relationship to students' readiness in terms of knowledge, skills, and abilities to deal with Technology. This study was conducted in several European countries (Latvia, Lithuania, Serbia, Poland, Belarus, and Romania). Two groups were taken, a group studying through e-learning and the second group in the traditional way. The study tool was distributed to them to decide the readiness of each of them for distance education, and the study concluded that not all students are equally ready when it comes to e-learning, and there are no approved standards developed to evaluate students.

Gaining knowledge in a global environment is becoming a widespread trend due to the ease of access and variety of online content encourage students to get involved in learning from digital resources [17]. Their study attempted to determine which factors affect students' attitudes towards e-learning. The questionnaire was given to (286) students. The results revealed that three factors were very important: e-learning usefulness, ease of use, and content design. All these factors in addition to regression had a significant influence on attitude towards e-learning. The online courses had a strong impact on students' e-learning intention.

As for the study of Al-Omari \& Eyadat [3], it aimed to reveal the perceptions of faculty members and students about the use of computerized tests in education at Yarmouk University. The study sample consisted of (120) faculty members, and of (380) students at Yarmouk University in Jordan, who were selected by random stratification. The study concluded that the perceptions of the faculty members and students were of a moderate degree. The results also indicated that there were statistically significant differences between the responses of faculty members and students due to the status variable in favour of students, and to the faculty variable in favour of humanitarian faculties.

Mulvaney [20] investigated in his study the effect of computerized tests on learning and retention of information by middle school students. Also, the study sought to know the extent of their accuracy in measuring student learning. The questionnaire was used to collect data from faculty members, and students of the sixth, seventh, and eighth grades in middle schools in rural areas in the American Midwest. The results of the study concluded that the opinion of teachers and students in those schools was highly positive about the concept of using computerized tests, that there is an ease in students' access to the computer, ease in dealing with computerized testing. Moreover, it saves the teacher's time and effort, and that the learners became more familiar while using this type of test with a positive attitude. Surprisingly, students expected to score higher on this type of test.

In the same vein, Stowell \& Bennett [31] illustrated the effect of electronic tests on reducing the level of test anxiety, which reflected positively on achievement. This study was applied to (69) university students who took two tests: paper and electronic tests. The results showed that students who suffered from test anxiety during traditional tests, their anxiety rate decreased significantly when they underwent the electronic test. On the other hand, it was noticed that an increase in test anxiety among students who do not suffer from anxiety in traditional tests. The relationship between test anxiety and performance in traditional test is weaker than in electronic tests.

Altmann [4] analyzed the concept of attitudes of nurses toward advancing formal education. The findings showed that the term 'attitude' was either not defined or vaguely defined. The cognitive, affective, and behavioural components are the vital attributes of an "attitude"; it is bipolar, and it is a response to a stimulus. These attributes interrelate to all aspects of intellect and behaviour. Thus, it is a controversial concept.

Foder [11] conducted a study aimed at developing a measure of attitudes towards online assessment. The sample of the study consisted of (231) faculty members at the University of Ankara in Turkey, an exploratory and confirmatory factor analysis was used to verify the validity of the scale construction. The results indicated that the scale consists of (3) factors with (26) items, and the loading of the factors ranged between (0.45) and (0.78), and the values of the items correlations coefficients ranged from $(0.20)$ to $(0.76)$, while the values of stability coefficients ranged from $(0.62)$ to $(0.91)$. The outcomes of the exploratory factor analysis were also done by extracting the confirmatory factor analysis, and the results showed that the measure of attitudes towards online tests 
was valid and reliable.

Previous studies dealt with various variables related to the subject of e-learning, such as students' readiness to deal with it and evaluation criteria of the electronic test performance similar to the study of [32].

Some studies indicated the positive effect of electronic tests in reducing the level of test anxiety among students and its impact on achievement, such as the study of Stowell \& Bennett [31]. Some of them also dealt with the positive effect of electronic tests in improving students' ability to retain information and its contribution to their learning, such as [20].

Earlier studies were related to identifying aspects of the theoretical framework and examined different variables. The current study differs from other studies in that it dealt with verifying the psychometric properties of the scale for assessing the quality of electronic tests presented to students, and identifying the strengths and weaknesses in them from the students' point of view, as this was not discussed in previous studies, according to the researchers' knowledge.

\section{Research Methodology}

The descriptive and analytical methods were used, which is the most appropriate to the nature of the study type.

\subsection{Study Population}

The study population consists of all the students of Amman Arab University, around (3000) students, according to the data of the Department of Admission and Registration for the second semester of the academic year (2019-2020).

\subsection{Study Sample}

The study sample consisted of (690) male and female students. They were selected according to the available sampling method, by sending the typed scale by Google forms via social media through the faculty members, as each faculty member has an electronic group for each course he teaches to communicate with the students.

\subsection{Study Tools}

\subsubsection{Scale of Student Attitudes toward Electronic Tests}

To answer the study questions, the attitude scale towards electronic tests was constructed; the scale objectives were determined by the global trends and the tendencies in revealing the difficulties and challenges facing the provision of distant exams. Some students were asked distantly about the most prominent challenges that they faced while administering the tests remotely.

Then, a group of items was built for the scale which in its initial form included (56) items. After completing the construction of the scale, it was presented to ten arbitrators and experts from the faculties' members in different universities in Jordan. They were asked to express their opinion on language integrity, the accuracy of wording, clarity of the items, to what extent of its suitability, its relevance to the subject of the study, adding and deleting what they see appropriate. Finally, their remarks were acted upon, and (10) items were deleted which the arbitrators agreed to omit.

The initial draft of the scale was also applied to an exploratory group of (30) students who are not included in the basic study sample in order to identify the extent of the clarity of the scale items and to make sure that it was valid. The researchers assured the students that it is important to answer each item of the scale seriously and express their opinion openly and they should inform the researchers in case one of the items was not understood or unclear, then it was collected. Their observations and responses were sorted out, and in light of these results, some items were reviewed to become clearer, some were merged, others were deleted, and thus the scale consisted in its final copy of (36) items.

\subsubsection{Reliability of the Scale}

In order to verify the reliability of the scale, it was applied to an exploratory sample consisting of (35) male and female students from outside the study sample, and after two weeks it was re-applied. The correlation coefficient (Pearson) between the two applications was calculated, reaching (0.86), which is appropriate for the current study, and the internal consistency was calculated using Cronbach's Alpha, with a value of (0.90).

\subsubsection{Checking the Normal Distribution of the Response of the Study Subjects}

The Kolmogorov-Simriov Test was used, with a value of (0.220) and a significant level of (0.090), which indicated that the response of the study sample individuals on the scale was normally distributed.

\subsubsection{The Cut scores of the scale:}

The five-point Likert ranking scale was used to judge on the arithmetic means of the students' attitudes toward the electronic tests according to the following equation: (the highest value in the ranking - the lowest value) / 3 . Thus, the categories are as follows:

From (1- 2.33) is low

$2.34-3.67)$ is Moderate

(3.68 -5) is High

\section{Statistical Treatment}

\section{The following statistical treatments were used:}

- Arithmetic means and standard deviations 
- Correlation coefficients, construct validity.

- First -order exploratory factor analysis using orthogonal axes.

- Standard Error of Measurement, and Discriminatory validity

- Two-Way ANOVA.

\section{Results and Discussion}

After finishing the second semester tests of the academic year (2019/2020), the study tool was implemented in the study sample. The final electronic tests varied between multiple choice, essay and open book tests, data were collected and analysed, and the results of the study questions are presented below:

\section{The first question: What are the indications of the validity of the attitude scale?}

First: the discriminatory validity of the scale was extracted:

The total average of the (690) students responses of the study sample, were arranged in descending order, then the two extreme groups were determined by taking $(27 \%)$ of the highest total degree and $(27 \%)$ of the lowest degree because this ratio makes the two groups to have the best possible size and good differentiation between them. Thus, the number of individuals in each of the two extreme groups was (186) and the discriminatory validity was calculated using the (t-test) for two independent samples to find out the significance of the difference between the mean scores of each group as shown in table (1).

It is noticed from Table (1) results that the value of ( $t$ ) reached (215.639), which is an indication of significance at the level of $(\alpha=0.05)$ in favour of the upper group, which indicates that the study tool has an appropriate discriminatory validity.

The results of the calculation of the items' discriminatory validity revealed that two items at the level of $(\alpha=0.05)$ were not significant and thus they were excluded from the scale in its final form which consisted of (34) items.

Second: Construct Validity:

The construct validity indicators were verified by finding the correlation of the items with the total score of the scale, where the values of the correlation coefficients results were positive and more than $(0.30)$ and statistically significant at the level of $(\alpha=0.01)$, and $(\alpha=0.05)$, expect (4) items which their correlations were less than $(0.28)$ and so they were excluded from the scale in its final form which consisted of (30) items.

\section{Third: Factor Validity:}

The validity of the scale factor was verified by performing a first-order Exploratory Factor Analysis on the sample as a whole using the principal component analysis method of the individuals' responses to the test items. The rotation was performed using the Varimax Rotation of the factors. For which the Eigenvalues were greater than (1), and the values of the Eigenvalues and the Explained Variance ratio were calculated for each of the factors, and Table (2) shows these results.

It is evident from the results of Table (2) that there are only three factors which Eigenvalues exceed (1) with explained variance $(58.45 \%)$ of the total variance in performance on the attitudes scale. The first factor was Eigenvalue reached (21.66) with explained variance ( $49.23 \%)$. The value of the Eigenvalue of the second factor was (2.92) and the amount of the explained variance on the scale was $(6.64 \%)$. It is noticed from the results of Table (2) that the ratio of the Eigenvalue of the first factor if compared to the Eigenvalue of the second factor has more than (2), which means it is one-dimensional verification concerning the features measured by the attitudes toward electronic tests scale.

Table 1. T-test results of two independent samples to examine the significance of discriminatory validity of the study instrument

\begin{tabular}{|c|c|c|c|c|c|}
\hline \multicolumn{2}{|c|}{} & Number & Arithmetic Mean & $\begin{array}{c}\text { Standard } \\
\text { deviation }\end{array}$ & Sig \\
\hline \multirow{2}{*}{ Total Degree } & Upper group & 186 & 4.93 & $\mathbf{0 . 0 9}$ & 215.639 \\
\cline { 2 - 6 } & Lower group & 186 & 2.60 & $\mathbf{0} .11$ & 0.001 \\
\hline
\end{tabular}

Table 2. The values of latent root value, explained variance and accumulative explained variance ratio

\begin{tabular}{|c|c|c|c|}
\hline Factor & Eigenvalue & \% Explained Variance Ratio & Accumulative Explained Variance Ratio \\
\hline 1 & 21.66 & 49.23 & 49.23 \\
\hline 2 & 2.92 & 6.64 & 55.86 \\
\hline 3 & 1.14 & 2.59 & 58.45 \\
\hline 4 & 0.80 & 1.83 & 60.28 \\
\hline
\end{tabular}




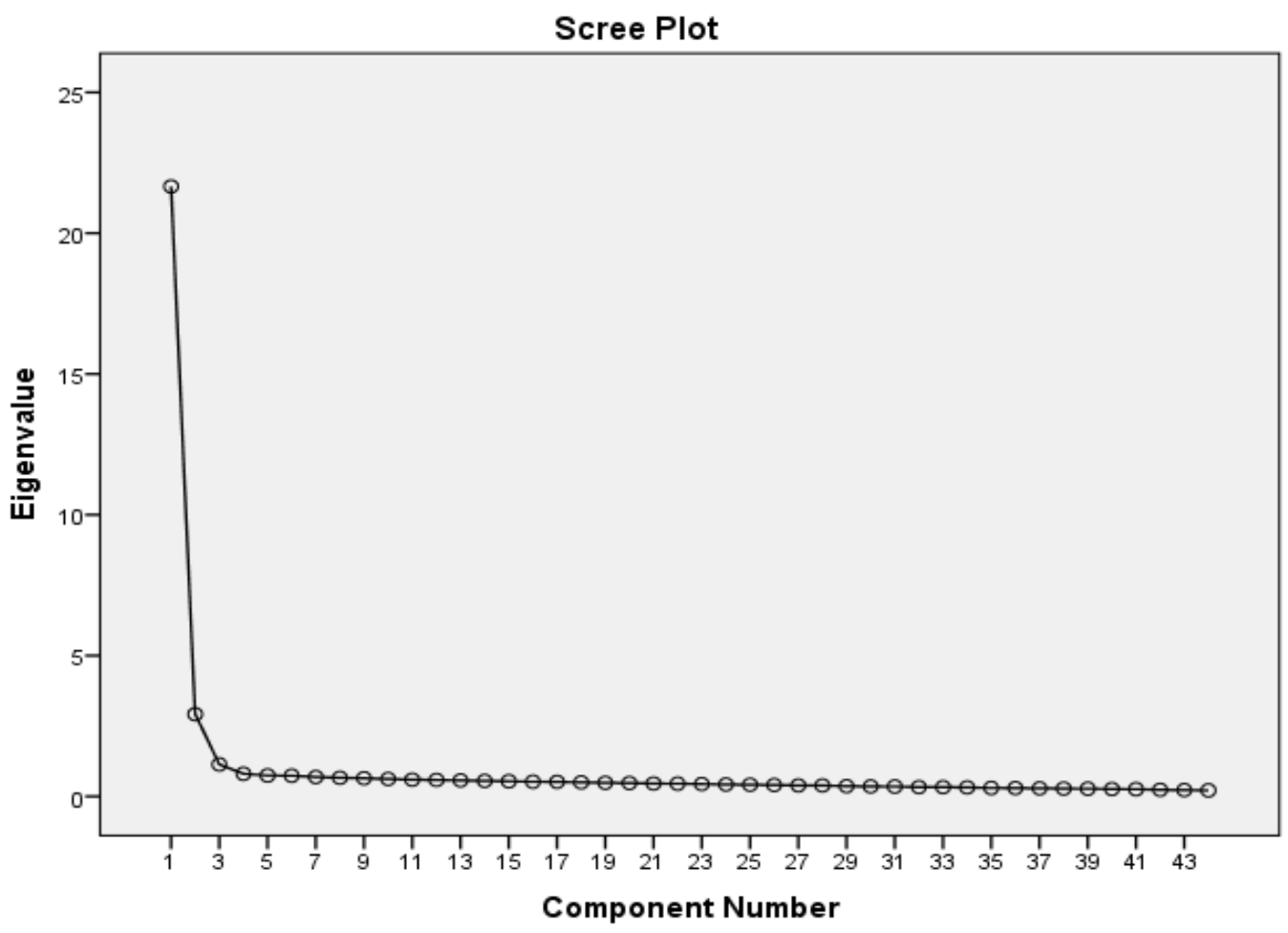

Figure 1. Graphical representation for the Eigenvalues of the attitude factors toward electronic tests

Figure (1) shows the factors with Eigenvalue that explain the attitudes variation scale in performance toward electronic tests. It is noticed that the value of the Eigenvalue of the first factor is large compared to that of the second Eigenvalue. It is worth mentioning that there is a shift in the curved slope at the second factor and a close continuity of the rest of the factors. This indicates the existence of a prevailing factor from which to infer the availability of a one-dimensional feature in performance on this scale. These findings can be attributed to the safety and accuracy of the procedures for building the scale and the implementation of it, as it confirms the seriousness of the study sample members in responding to this scale and the appropriateness of the statistical tests taken to answer the questions of the study.

These results are consistent with the results of the study of Al-Omari \& Eyadat [3] whose results showed that the validity statistical procedure for the attitude scale towards on-line assessment has indicated that it was valid.

The second question: What are the indications of the reliability of the attitude scale towards electronic tests?

The reliability parameters were verified by the following methods:

First: internal consistency using the Cronbach's Alpha equation.

It was extracted on the main sample $(\mathrm{N}=690)$ and its value was $(0.85)$, which is a high value suitable for the current study.

Second: reliability using Split-half procedure:

Its value was $(0.88)$, which is considered an appropriate value for the current study.

\section{Third: Standard Error of Measurement:}

The standard error of measurement was found for the total degrees, where the standard error is used as an indicator of reliability, and its value was (0.007), which indicates a high and appropriate reliability coefficient.

Fourth: Using the Hoyt equation as an indicator of the internal homogeneity of the items through using the variance between groups and the variance within groups, the value was $(0.82)$ which is considered an appropriate value for the current study purposes.

These findings can be attributed to the safety and accuracy of the procedures for building the scale and its implementation. It confirms the seriousness of the study sample members in responding to this scale and the appropriateness of the statistical tests taken to answer the questions of the study. This indicates the reliability of the scale in measuring students' attitude toward electronic tests, the Cronbach's Alpha values, and the standard error of estimate confirmed these outcomes.

These results are consistent with the results of the study of Gul et, al. [13] whose results showed that the reliability statistical procedure for the attitude scale toward online assessment has indicated that it was similarly valid. 
The third question: What are the attitudes of graduate students towards electronic tests in Jordan?

Table (3) results indicate the level of students' attitudes toward electronic tests was moderate, as the arithmetic mean was (3.61) with a standard deviation (0.92), in the first rank came item (27) which stated: "Presenting the test through the phone confused me," with the mean of (4.58) and a standard deviation (0.96), and in the last rank came item (6), which stated: "Moving between test questions was easy." with a mean (2.56), and a standard deviation (1.77), with a moderate level.

Table 3. Arithmetic means and standard deviations of students' attitudes towards electronic tests

\begin{tabular}{|c|c|c|c|c|c|}
\hline $\begin{array}{c}\text { Item } \\
\text { Number }\end{array}$ & Item & $\begin{array}{c}\text { Arithmetic } \\
\text { Mean }\end{array}$ & $\begin{array}{l}\text { Standard } \\
\text { Deviation }\end{array}$ & Rank & Level \\
\hline 27 & Presenting the test through the phone confused me & 4.58 & 0.96 & 1 & high \\
\hline 24 & $\begin{array}{c}\begin{array}{c}\text { Not having a paper copy of the questions in front of me made } \\
\text { me nervous }\end{array} \\
\end{array}$ & 4.38 & 1.12 & 2 & high \\
\hline 29 & I couldn't give every question enough time to answer & 4.38 & 0.81 & 3 & high \\
\hline 28 & Staring at a computer screen made my eyes tired & 4.21 & 0.98 & 4 & high \\
\hline 23 & $\begin{array}{l}\text { Submitting electronic tests requires computer skills that I do } \\
\text { not have }\end{array}$ & 4.12 & 1.20 & 5 & high \\
\hline 21 & $\begin{array}{l}\text { Some of my colleagues tried to contact me during the test } \\
\text { submission to get some answers }\end{array}$ & 4.10 & 1.13 & 6 & high \\
\hline 4 & $\begin{array}{l}\text { I see that a computerized test is no different than a } \\
\text { paper-based test }\end{array}$ & 3.97 & 1.23 & 7 & high \\
\hline 13 & The test instructions were not clear & 3.91 & 1.27 & 8 & high \\
\hline 20 & I didn't have a suitable atmosphere to take the test at home & 3.91 & 1.19 & 9 & high \\
\hline 19 & $\begin{array}{l}\text { My inability to postpone some questions until the end to } \\
\text { gather my thoughts affected negatively on my performance }\end{array}$ & 3.80 & 1.19 & 10 & high \\
\hline 17 & The presence of a timer on the test screen confused me & 3.74 & 1.71 & 11 & high \\
\hline 10 & $\begin{array}{c}\text { Unavailability of having a laptop made it difficult to deliver } \\
\text { the test }\end{array}$ & 3.72 & 1.52 & 12 & high \\
\hline 14 & $\begin{array}{l}\begin{array}{l}\text { Not being able to go back to review the questions confused } \\
\text { me }\end{array} \\
\end{array}$ & 3.72 & 1.39 & 13 & high \\
\hline 22 & $\begin{array}{l}\text { I feel that my scores on the electronic tests do not reflect my } \\
\text { true knowledge of the course }\end{array}$ & 3.71 & 1.20 & 14 & high \\
\hline 7 & I suffered from internet interruption during the test & 3.65 & 1.48 & 15 & moderate \\
\hline 1 & I was able to perform remote tests easily & 3.62 & 1.00 & 16 & moderate \\
\hline 30 & The university's testing system have problems & 3.62 & 1.32 & 17 & moderate \\
\hline 3 & I had access to the test easily & 3.56 & 1.72 & 18 & moderate \\
\hline 11 & My slow typing hindered my performance for the test & 3.42 & 1.43 & 19 & moderate \\
\hline 9 & $\begin{array}{l}\text { The questions were not arranged from the easiest to the most } \\
\text { difficult }\end{array}$ & 3.38 & 1.57 & 20 & moderate \\
\hline 16 & $\begin{array}{c}\text { The space allocated to answer the essay questions was not } \\
\text { enough }\end{array}$ & 3.32 & 1.32 & 21 & moderate \\
\hline 8 & The order of test questions confused me & 3.26 & 0.91 & 22 & moderate \\
\hline 25 & $\begin{array}{l}\text { The lack of diversity of questions in the online test affected } \\
\text { my score negatively }\end{array}$ & 3.23 & 1.78 & 23 & moderate \\
\hline 26 & $\begin{array}{l}\text { The lack of sequence in the presentation of the items of the } \\
\text { same question distracted my thinking }\end{array}$ & 3.20 & 1.38 & 24 & moderate \\
\hline 5 & $\begin{array}{l}\text { It would be desirable if all the tests became electronic } \\
\text { remotely }\end{array}$ & 3.19 & 1.60 & 25 & moderate \\
\hline 15 & The wording of some of the questions was not clear & 3.19 & 1.76 & 26 & moderate \\
\hline 2 & Time allotted for remote tests was sufficient & 3.15 & 1.55 & 27 & moderate \\
\hline 18 & $\begin{array}{l}\text { Not knowing the remaining questions caused me anxiety and } \\
\text { stress }\end{array}$ & 2.96 & 1.71 & 28 & moderate \\
\hline 12 & Screen colors and font were not comfortable & 2.80 & 1.38 & 29 & moderate \\
\hline 6 & Moving between test questions was easy & 2.56 & 1.77 & 30 & moderate \\
\hline & Total Degree & 3.61 & \multicolumn{2}{|c|}{0.92} & moderate \\
\hline
\end{tabular}


The arithmetic mean of items (27), (24), (29), and (23) was high. These items reveal one of the factors that could affect students' attitudes and perspectives on Distance learning is their poor skills and experience in using technologies. Students faced some problems due to the lack of technical skills or not having PCs or laptops. They need to practice a long time to become faster in typing (item 11) and perform the electronic tests adequately and fast. The results were compatible with Al-Omari \& Eyadat, Rostaminezhad $[3,25]$ that a negative attitude and lack of computer skills impede the process of learning.

On the other hand, students who love technology and the know-how to use it easily admitted that they scored better grades in electronic tests as noticed in items (1), (3), and (6). This result is parallel to Mulvaney, Stowell \& Bennet [20, 31] where a positive attitude increases learning and has better retention of the course content. The outcome of Peytcheva-Forsyth, Stowell\& Bennett, Worrell et, al $[23,32]$ studies results were reflected in items (4), (2), and (5) where students showed readiness to use technology and motivated to do electronic tests.

The fourth question: Do graduate students' attitudes towards electronic tests differ according to gender and faculty?

To answer this question Arithmetic averages and standard deviations were also found for different faculties and gender, as seen in Table (4).

Table 4. Arithmetic means and standard deviations for student attitudes towards electronic tests according to gender and faculty

\begin{tabular}{|c|c|c|c|c|}
\hline Gender & Faculty & $\begin{array}{c}\text { Arithmetic } \\
\text { means }\end{array}$ & $\begin{array}{c}\text { Standard } \\
\text { deviation }\end{array}$ & number \\
\hline \multirow{4}{*}{ Male } & Humanitarian & 3.62 & 0.99 & 139 \\
\cline { 2 - 5 } & Scientific & 3.47 & 0.89 & 204 \\
\cline { 2 - 5 } & Total & 3.53 & 0.94 & 343 \\
\hline \multirow{4}{*}{ Female } & Humanitarian & 3.65 & 0.95 & 136 \\
\cline { 2 - 5 } & Scientific & 3.72 & 0.97 & 211 \\
\cline { 2 - 5 } Total & Total & 3.69 & 0.96 & 347 \\
\hline \multirow{3}{*}{} & Humanitarian & 3.63 & 0.97 & 275 \\
\cline { 2 - 5 } & Scientific & 3.60 & 0.94 & 415 \\
\cline { 2 - 5 } & Total & 3.61 & 0.95 & 690 \\
\hline
\end{tabular}

Table (4) results reveal that there are apparent differences between the arithmetic means of the attitudes towards electronic tests according to gender and faculty, and to find out whether these differences are statistically significant, a Two-Way analysis of variance was extracted as shown in Table (5).

It is noteworthy that the results of Table (5) point out there are no statistically significant differences attributed to the faculty or the interaction between the faculty and gender variables. This outcome was incompatible with Mulvaney [20] study that faculty members have a statistically significant difference.
Table 5. The results of the Two-Way analysis of variance for exploring the significance of the differences between the arithmetic means of students' attitudes towards electronic tests

\begin{tabular}{|c|c|c|c|c|c|}
\hline $\begin{array}{c}\text { Variance } \\
\text { source }\end{array}$ & $\begin{array}{c}\text { Sum of } \\
\text { square }\end{array}$ & $\begin{array}{c}\text { Degree } \\
\text { of } \\
\text { freedom }\end{array}$ & $\begin{array}{c}\text { Mean } \\
\text { square }\end{array}$ & $\mathrm{f}$ & Sig \\
\hline Gender & 3.160 & 1 & 3.160 & 3.518 & 0.041 \\
\hline Faculty & 0.202 & 1 & 0.202 & 0.225 & 0.635 \\
\hline Gender*faculty & 1.910 & 1 & 1.910 & 2.126 & 0.145 \\
\hline Error & 616.260 & 686 & 0.898 & & \\
\hline Total & 9628.877 & 690 & & & \\
\hline
\end{tabular}

This may be explained because the majority of the student in all faculties know how to deal with electronic tests, also the computer-department in the university released some videos that train the student on how to perform the electronic test. Many faculty members attended intensive workshop regarding preparing for electronic tests which helped them to guide the student in this regard and solve emerging problems. However, there were statistically significant differences at the level of $(\alpha$ $=0.05$ ) attributed to gender, as the value of " $F$ " reached (3.518). Returning to the table of arithmetic means, it is noticed that the differences are in favor of females students.

This result may be attributed to the fact that many of the female students are working women with families and children. Therefore, it is very comfortable for them to do electronic tests from their homes rather than driving to university and spending hours away on the university campus.

These results were consistent with what has indicated in Mulvaney [20] study that students became more familiar using this type of tests with a positive attitude, also the study results were consistent relatively with Stowell \& Bennett [31] study which indicated that students anxiety rate decreased significantly when they underwent the electronic tests.

Meanwhile, there is relatively inconsistency with what was indicated in Rostaminezhad[25] study which revealed that student's attitude was very contradicting in the instant feedback features of electronic tests; because some felt immediate feedback is stressful others considered it pleasing.

\section{Conclusions}

After using the appropriate statistical measures we had reached a scale with good psychometric properties, and after applying the scale, the analysis allowed us to draw some important conclusions regarding the perspectives and attitudes of the graduate students from Amman Arab University towards electronic tests.

Students have a moderately positive attitude towards electronic tests, which implies that they would agree to 
use it as a mode of education. It could be concluded that students' main desires to use an effective environment with integrated technologies among students, online assignment submission, electronic tests, and the teacher.

The results concerning the impact of the demographic factors such as gender and faculty on the graduate students' attitudes towards electronic tests confirmed that the results were in favor of female students. However, the faculty variable played an insignificant role.

Generally, the results of this study are encouraging in terms of an introduction to Distance learning because they demonstrate the willingness and the positive attitudes of numerous graduate students to the use of technology in education. Forthcoming steps for Amman Arab University are related to the integration of technology into academic teaching without neglecting the importance of traditional teaching.

\section{Recommendations}

Based on the analysis of the findings of the current study the researchers suggest the following recommendations be taken into consideration in the future:

1. Conducting various studies regarding other variables to see to what extent the results obtained here match those obtained from other universities. This would provide a more comprehensive view of electronic tests among different countries and universities.

2. Teachers can use Distance learning for designing and developing electronic tests in their formative and comprehensive assessments and benefit from the graduate students' feedback for their assessments. This research will help teachers to select and use electronic tests with deeper insight and will help them to consider its limitations.

3. Researchers might investigate the conditions and factors that might affect positively or negatively graduate students' attitudes toward electronic learning.

4. Using the scale of this study would be beneficial for other studies because of its appropriate psychometric properties.

\section{REFERENCES}

[1] Abdul Salam, I.\& Hassan, A. The effectiveness of the electronic test in the process of evaluating the performance of academic achievement tests in postgraduate studies, an unpublished master's thesis, Sudan University of Science and Technology, 2017.

[2] Al-Ghamdi, S. The Effectiveness of Web-Based Electronic Training in Developing Electronic Test Preparation Skills for High School Teachers in Jeddah, Fayoum University's
Journal of Educational and Psychological Sciences, Vol.4, No.7 pp. 243-274, 2017.

[3] Al-Omari, M \& Eyadat, Y. Perceptions of faculty members and students about computerized tests in the teaching-learning process at Yarmouk University. The Jordanian Journal of Educational Sciences, Vol.12, No.4, pp. 478-469, 2016.

[4] Altmann, T. Attitude: A Concept Analysis, Nursing forum. Research Gate. Vol.43, pp.144-50.2008. DOI: 10.1111/j.17 44-6198.2008.00106.x

[5] Byrd, B., \& Lott, K. Evaluation in online courses. Business Education Forum, Vo.58, No.1, pp. 48-50, 2003.

[6] Christopher, M. M., Thomas, J. A., \& Tallent-Runnels, M. K. Raising the bar: Encouraging high level thinking in online discussion forums. Roeper Review, Vol. 26, No.3, pp.166-171, 2004.

[7] Davidson, P. Why Technology Has Had Only A Minimal Impact On Testing In Education. Educational Technology Conference Proceedings, Sultan Qabus University, Oman, pp.65-79, 2003.

[8] Debuse, J. C. W., \& Lawley, M. Benefits and drawbacks of computer-based assessment and feedback systems: Student and educator perspectives. British Journal of Educational Technology, Vo.47, No.2, pp.294-301, 2016. https://doi.org /10.1111/bjet.12232.

[9] Evans, C. D. Understanding assessment. The Delta Pi Epsilon Journal, Vol.44, No.1, 3-12.2002.

[10] Ezza, E., \& Almudibry, K. ICT as an index of transparency in a Saudy EFL classroom. TESOL International Journal. No.13, Vo.1, pp.76-81, 2018.

[11] Fodor, J. T. Online college courses: Great for some people-not so great for others. Promotion \& Education, Vol.10, No.2, pp.72-83, 2003.

[12] Gaytan, Jorge. Effective Assessment Techniques for Online Instruction. Information Technology - IT. Vo.23, pp. 34-45, 2004.

[13] Gul. E., Cokluk, O., and Gul., C. Development of an Attitudes Scale toward Online Assessment, Procedia Social and Behavioral Sciences, Vol. 174, pp.529-536, 2015, doi: 10.1016/j.sbspro.2015.01.699,

[14] Hatfield, S. R., \& Gorman, K. L. Assessment in education-the past, present, and future. Assessment in Business Education National Business Education Association Yearbook, 38, pp.1-10. Reston, VA: National Business Education Association. 2000.

[15] Heberling, M. Maintaining academic integrity in online education. Online Journal of Distance Learning Administration, Vol.5, No.1, pp.67-75, Retrieved June 15, 2003, from http://www.westga.edu/\%7Edistance/ojdla/sprin g51/spring51, 2002.

[16] Hellystia, D. Web-based blended learning for EFL reading in the university context in Indonesia. Asian EFL Journal, Vol.23, No.6, pp.202-213, 2019.

[17] Jović, M., Kostic Stankovic, M., \& Neskovic, E. Factors Affecting Students' Attitudes towards E-Learning. Management: Journal of Sustainable Business and 
Management Solutions in Emerging Economies.Vol.22, No.2, pp.15-21, 2017. doi: 10.7595/management.fon.0016.

[18] MacKinnon, G. R. Practical advice for first time online instructors: A qualitative study. Journal of Instructional Delivery Systems, No.16, Vol.1, pp. 21-25, 2002.

[19] Mohammed. Ziani. Psychometric Characteristics of the Sarson Test Anxiety Scale for a Sample of Secondary School Students, Unpublished MA Thesis, Abdel Hamid Ibn Badis University, Mostaganem, Algeria., 2018.

[20] Mulvaney, J. Computer-based Assessment and the Effects it has an Middlo Srhonl Aood Students Doctoral dissertation, University of Wisconsin, Stout, 2011.

[21] Muir-Herzig, R. G. (2004). Technology and its impact in the classroom. Computers \& Education, Vol.42, No.2, pp.111-131, 2004.https://doi.org/10.1016/S0360-1315(03)00067-8.

[22] Perrin, K. M., \& Mayhew, D. The reality of designing and implementing an internet-based course. Online Journal of Distance Learning Administration, Vol.3, No.4, pp. 44-53, 2000 .

[23] Peytcheva-Forsyth, R., Yovkova1, B, \& L. Factors affecting students' attitudes towards online learning - The case of Sofia University. AIP Conference Proceedings Vol.2048, (2018); https://doi.org/10.1063/1.5082043.

[24] Robles, M., \& Braathen, S. Online Assessment Techniques. The Delta Pi Epsilon Journal, Vol. 44, No. 1, pp.39-49, 2002.

[25] Rostaminezhad, M. Students' Perceptions of the Strengths and Limitations of Electronic Tests Focusing on Instant Feedback. Journal of Information Technology Education: Research, Vol.18, pp.59-71, 2019

[26] Scanlon, P. M. Student online plagiarism: How do we respond? College Teaching, Vol. 51, No.), pp.161-165, 2003.

[27] Shute, V. J., \& Rahimi, S. Review of computer-based assessment for learning in elementary and secondary education. Journal of Computer Assisted Learning, Vol 33, No.1, pp. 1-19, 2017. https://doi.org/10.1111/jcal.12172.

[28] Singh, P., \& Pan, W. Online education: Lessons for administrators and instructors. College Student Journal, Vol. 38, No.2, pp. 302-316, 2004.

[29] Sivula, M \& Robson, E. "E-testing in Graduate Courses: Reflective Practice Case Studies", MBA Faculty Conference Papers \& Journal Articles. Vol. 87, 2015.

[30] Sözen, E. \& Güven, U. (2019). The Effect of Online Assessments on Students' Attitudes Towards Undergraduate-Level Geography Courses, International Education Studies; Vo. 12, No.10, pp. 22-39,2019. doi:10.5539/ies.v12n10p1.

[31] Stowell, J. and Bennett, D. Effects of Online Testing on Student Exam Performance and Test Anxiety. Journal of Educational Computing Research. Vol. 42, No.2, 161-171, 2010.

[32] Vasilevska. B, Rivza. D, \& Bogdan. R . Evaluation of Readiness for Distance Education of Students in European Universities. BRAIN: Broad Research in Artificial Intelligence and Neuroscience, Vol. 8, pp.35-42, 2017

[33] Worrell, J., Duffy, M. L., Brady, M. P., Dukes, C., \& Gonzalez-DeHass, A. Training and generalization effects of a reading comprehension learning strategy on computer and paper-pencil assessments. Preventing School Failure: Alternative Education for Children and Youth, Vol.60. No.4 pp. 267-277, 2016, doi.org/10.1080/1045988X.2015.11164 30. 